\title{
O PAPEL FAMILIAR NO PROCESSO PSICOPEDAGÓGICO
}

\author{
THE FAMILY ROLE IN THE PSYCHOPEDAGOGIC PROCESS
}

\section{EL PAPEL FAMILIAR EN EL PROCESO PSICOPEDAGÓGICO}

\author{
Lívia Anicet Zanini \\ Mestrado em Psicologia Escolar e do Desenvolvimento Humano - USP - São Paulo \\ Especialização em Psicopedagogia Clínica e Institucional - Faculdades Integradas de Jaú \\ E-mail: liviaanicet@gmail.com \\ Elaine Cristina Gardinal Pizato \\ Doutora em Psicologia - Faculdade de Filosofia Ciências e Letras de Ribeirão Preto - USP \\ Docente das Faculdades Integradas de Jaú \\ E-mail: egardinal@yahoo.com.br
}

\begin{abstract}
RESUMO
A partir da ideia de que as famílias estão sempre implicadas nos processos de acompanhamento psicopedagógico, pretendeu-se problematizar qual é o papel que os psicopedagogos atribuem a função familiar neste processo. Tratou-se, portanto, de uma pesquisa de cunho exploratório, na medida em que procurou conhecer mais a respeito do tema da participação familiar no acompanhamento psicopedagógico, utilizando-se, para isso, de pesquisa bibliográfica nos sites de pesquisa Scielo, Google Acadêmico e Revista de Psicopedagogia da Associação Brasileira de Psicopedagogia. Desta forma, foi possível discutir e refletir a respeito de trabalhos que: enfatizam a influência de modalidades de aprendizagem dos pais sobre às formas de aprender de seus filhos; destacam a importância de determinadas estratégias familiares para o fortalecimento da aprendizagem dos seus filhos; apresentam propostas de algumas orientações e realização de grupos de reflexão com as famílias de crianças e adolescentes com dificuldades de aprendizagem. Refletir sobre o papel que se atribui às famílias nos processos de aprendizagem torna-se importante para a realização de um trabalho psicopedagógico não culpabilizante das relações familiares.
\end{abstract}

Palavras-chave: família. acompanhamento psicopedagógico. dificuldades de aprendizagem.

\begin{abstract}
Based on the idea that families are always involved in the processes of psychopedagogical monitoring, it was intended to problematize what role psychopedagogues attribute to family function in this process. Therefore, it was an exploratory research that sought to know more about family participation in psycho-pedagogical accompanimen, using for this of bibliographic research in search engines such as Scielo, Google Scholar and the Journal of Psychopedagogy of the Brazilian Association of Psychopedagogy. In this way, it was possible to discuss and reflect on works that: emphasize the influence of parents' learning modalities on their children's ways of learning; highlight the importance of certain family strategies for strengthening the learning of their children; present proposals for some guidelines and the results of discussion
\end{abstract}

$$
\text { RELEDUC | ISE } \mid \text { v. } 3 \text { | n. } 1 \text { | dez. } 2020
$$


groups with families of children and adolescents with learning difficulties. Reflecting on the role attributed to families in the learning processes becomes important for carrying out psychopedagogical work that does not blame family relationships.

Keywords: family. psychopedagogical monitoring. learning difficulties.

RESUMEN: Partiendo de la idea de que las familias siempre están involucradas en los procesos de acompañamiento psicopedagógico, se pretendió problematizar cuál es el rol que los psicopedagogos atribuyen a la función familiar en este proceso. Se trató, por tanto, de una investigación exploratoria, en la medida en que buscó conocer más sobre el tema de la participación familiar en el seguimiento psicopedagógico, utilizando la investigación bibliográfica en los sitios de investigación Scielo, Google Acadêmico y Revista de Psicopedagogia da Associação Brasileira de Psicopedagogia. De esta manera, fue posible debatir y reflexionar sobre trabajos que: enfatizan la influencia de las modalidades de aprendizaje de los padres en las formas de aprendizaje de sus hijos; destacar la importancia de ciertas estrategias familiares para fortalecer el aprendizaje de sus hijos; presentar propuestas de pautas y realizar grupos de reflexión con las familias de niños y adolescentes con dificultades de aprendizaje. Reflexionar sobre el papel atribuido a las familias en los procesos de aprendizaje se torna importante para realizar una labor psicopedagógica que no culpe a las relaciones familiares.

Palabras clave: la familia. seguimiento psicopedagógico. dificultades de aprendizaje.

\section{INTRODUÇÃO}

Muitos estudos indicam que a família tem um papel imprescindível na aprendizagem de seus filhos, apontando para a importância de se fortalecer a relação família-escola para a potencialização da educação e desenvolvimento das crianças (OLIVEIRA; MARINHOARAÚJO, 2010). Por outro lado, também advertiu Nogueira (2006): “é preciso, entretanto, esclarecer que - do ponto de vista científico - não é possível, no estágio atual das pesquisas, estabelecer relações inequívocas entre a implicação familiar e o desempenho escolar”. Apesar de se considerar essa ressalva, é importante lembrar que os estudos psicopedagógicos necessariamente trazem a importância de se chamar as famílias para o processo de acompanhamento dos seus filhos com dificuldades de aprendizagem: "A avaliação psicopedagógica desenvolve-se em colaboração com o conjunto de participantes no processo: os alunos, a família, a escola, outros profissionais, etc." (COLOMER; MASOT; NAVARRO, 2008, p. 16). As autoras, posteriormente, explicam que: “A família é o primeiro núcleo de socialização das crianças e facilita, em maior ou menor grau, as interações para a inserção escolar e social" (idem, p. 21). Almeida (2011), por sua vez, abordando as modalidades de aprendizagem e sua construção, destaca que:

$$
\text { RELEDUC | ISE } \mid \text { v. } 32 \text { | n. } 1 \text { | dez. } 2020
$$


A modalidade de aprendizagem se constrói pelo como os ensinantes reconheceram e desejaram a criança como sujeito aprendente e a significação que o grupo familiar deu ao ato de conhecer. Por esse motivo, o sujeito jamais poderá ser considerado, dentro da perspectiva psicopedagógica, fora do seu campo familiar (p. 202).

Gomes e Vale-Dias (2017), em seu artigo sobre a construção de modalidades de aprendizagem e a implicação da família nessa construção, escrevem que:

Nesse sentido, a família é o principal grupo social onde o sujeito está inserido, tendo como essenciais educadores ou "ensinantes" os seus pais. A modalidade de aprendizagem acontece conforme os vínculos estabelecidos com o modus operandi da circulação do conhecimento na família. Cabe também mencionar a forma como o sujeito "aprendente" é visto pela família, como o grupo lida com as situações de divergências, ou se esse sujeito manifesta ou não os seus sentimentos e/ou opiniões, se é ou não ouvido pelo núcleo familiar. (p.313)

Nessa citação, por exemplo, destaca-se a importância que é dada pelas reações da família para o desenvolvimento da modalidade de aprendizagem da criança e/ou adolescente. Marturano e Elias (2016) procuraram estudar o valor preditivo de fatores de queixa escolar, adversidades familiares e apoio ao desenvolvimento para problemas de comportamento em escolares:

A partir do exposto vemos que no anos escolares, família e escola são contextos onde se engendram mecanismos de risco e proteção para trajetórias mais ou menos favoráveis de desenvolvimento. Problemas de comportamento podem surgir em decorrência do acúmulo de adversidades nos dois contextos. Em contrapartida, há indícios de que famílias que oferecem apoio ao desenvolvimento das crianças, por meio de rotinas regulares, oportunidades de interação com os pais e acesso ao lazer diversificado, operam de forma protetora[...]. (p. 126).

No fim desse artigo, por exemplo, as autoras sugerem uma simples orientação às famílias como forma de disponibilizarem apoio aos seus filhos, como a realização de uma rotina regular e a diversificação de atividades de lazer em casa. Silva (2015), por sua vez, enfocou a importância da relação entre família e escola na aprendizagem da criança com transtorno de déficit de atenção e hiperatividade (TDAH). Em seu trabalho constata-se a necessidade dessa interação, ressaltando a participação familiar para a boa aprendizagem de crianças com TDAH:

Escola e família trabalhando em cooperação aumentam a probabilidade da criança ter uma experiência de vida escolar bem-sucedida. A criança com TDAH possui dificuldades as quais os pais e a escola precisam trabalhar unidos para que esse aluno possa alcançar sucesso. [...] 
É importante existir uma comunicação dos pais com a coordenação da escola para entender como a instituição lida com alunos com TDAH, e se os professores contam com orientações específicas para auxiliar o processo de aprendizagem de crianças que possuem déficit de atenção e hiperatividade (p. 7).

Desta forma, a partir da problematização dessa implicação da família no processo psicopedagógico, o tema de pesquisa desse trabalho é a relação do trabalho da psicopedagogia e a participação familiar nesse processo. $\mathrm{O}$ seu objetivo pode ser resumido da seguinte maneira: segundo a visão da psicopedagogia, qual é o papel da família no processo de acompanhamento psicopedagógico? A partir da ideia de que as famílias estão sempre implicadas nos processos de acompanhamento psicopedagógico, pretende-se problematizar qual é o papel que os psicopedagogos atribuem a função familiar neste processo: quais expectativas possuem quanto ao papel familiar? Realizam orientações do que as famílias devem fazer? Se sim, como essas orientações são realizadas? As famílias possuem algum tipo de apoio direcionado a elas durante esse processo?

Assim, tem-se como objetivos específicos: investigar as expectativas dos psicopedagogos quanto a participação familiar no processo de acompanhamento psicopedagógico; descrever os papéis comumente atribuídos às famílias na educação de seus filhos por psicopedagogos; pesquisar a realização de orientações às famílias nos processos de acompanhamento psicopedagógico; explorar a existência de trabalhos de apoio às famílias com filhos em processos de acompanhamento psicopedagógicos; sugerir uma proposta de grupos de acompanhamento das famílias de crianças e/ou adolescentes atendidos por psicopedagogos.

\section{METODOLOGIA}

É necessário considerar o papel atribuído a família no contexto social, histórico e político atual e pensar a maneira de como se tornaram necessárias determinadas demandas às famílias ao longo do tempo: “[...]as pesquisas orientadas pelo método dialético, revelam a historicidade do fenômeno e suas relações em nível mais amplo situam o problema dentro de um contexto complexo, e, ao mesmo tempo, estabelece e aponta as contradições possíveis dentre os fenômenos investigados.”(BORGES; DALBERIO, 2007). Esta pesquisa tem como objetivo investigar o papel da família no processo psicopedagógico, segundo a visão da psicopedagogia. As técnicas utilizadas para este trabalho incluíram:

$$
\text { RELEDUC | ISE } \mid \text { v. } 34 \text { n. } 1 \text { | dez. } 2020
$$


- Pesquisa bibliográfica de artigos sobre a participação familiar nos acompanhamentos psicopedagógicos;

- Análise da forma como o papel familiar é visto nos processos de aprendizagem de alunos ao longo do período de existência da revista eletrônica da Associação Brasileira de Psicopedagogia (ABPp), de 2003 até 2018;

Tratou-se, portanto, de uma pesquisa de cunho exploratório, na medida em que procurou conhecer mais a respeito do tema da participação familiar no acompanhamento psicopedagógico.

Os critérios para a seleção dos artigos para análise foram:

- busca nos sites de busca Google Acadêmico, Scielo e Revista de Psicopedagogia dos seguintes termos: "psicopedagogia" E "família"; "problemas de aprendizagem" E família"; “dificuldades de aprendizagem" E família".

- foram selecionados os artigos do período definido anteriormente (2003 a 2018) e que tivessem em seus resumos o enfoque da importância do acompanhamento familiar para processos de aprendizagem e/ou de dificuldades de aprendizagem;

- foram selecionados os estudos que pensassem os processos de aprendizagem e suas dificuldades em crianças e adolescentes, excluindo-se os estudos com o ensino superior;

- os trabalhos deveriam ser no idioma português e brasileiros.

\section{RESULTADOS E DISCUSSÕES}

A seguir, iremos destacar os resultados mais importantes de acordo com os objetivos desse estudo. Esses resultados foram produzidos a partir da leitura e análise dos artigos encontrados de acordo com a metodologia proposta. Desta forma, foram agrupadas grandes temáticas abordadas nos estudos selecionados e em seguida são discutidos trechos e exemplos encontrados nos artigos específicos. Alguns artigos, apesar de lidos, não foram citados na medida em que repetiam informações já exemplificadas a partir de outros estudos.

\section{Expectativas do papel familiar na aprendizagem}

De maneira geral, os estudos encontrados enfatizam a importância do papel familiar para a modelagem e facilitação dos processos de aprendizagem das crianças, principalmente na primeira infância:

$$
\text { RELEDUC | ISE } \stackrel{75}{75} 3 \mid \text { n. } 1 \text { | dez. } 2020
$$


[...]a intervenção da Psicopedagogia não pode se dirigir ao sintoma da nãoaprendizagem, mas sim aos fatores envolvidos na sua formação, mobilizando a modalidade de aprendizagem do sujeito e da sua família. Todo tratamento ou toda ação psicopedagógica precisa mobilizar a circulação do conhecimento no grupo familiar. (BRAGA; SCOZ; MUNHOZ, 2007, p. 158)

Em sua maioria, apesar de destacarem a relevância do ambiente familiar para o desenvolvimento dos processos de aprendizagem das crianças, os estudos defendem que não se pode ter uma visão linear a respeito dos fatores que podem levar às dificuldades de aprendizagem, na medida em que são muito diversos e o papel da família é apenas um deles. De fato, com relação a visão específica dos profissionais psicopedagogos, o trabalho de Salvari e Dias (2006), que realizou entrevistas com psicopedagogos sobre os motivos para um tratamento psicopedagógico, destaca que: "Todas as entrevistadas citaram aspectos psicodinâmicos da família como possíveis dificultadores da aprendizagem da criança" (p. 256).

Os estudos que procuravam compreender a visão de professores a respeito das dificuldades de aprendizagem traziam uma visão desses profissionais associada a uma culpabilização do ambiente familiar para os problemas de aprendizagem de seus alunos:

A literatura científica sobre o tema tem assinalado que os professores, quando questionados sobre a causa das dificuldades de aprendizagem, apontam predominantemente fatores relacionados às crianças e/ou às famílias. (NETO et al., 2015, p. 33)

Nesta pesquisa quando os professores foram questionados sobre as três possíveis atitudes em relação às crianças com dificuldades escolares, as opções de respostas selecionadas por eles, tanto nas escolas públicas como nas escolas privadas, foram, em ordem decrescente, conversar mais como aluno (85\%) e investigar a família (70\%). (TABILE; JACOMETO, 2017, p. 82)

Desta forma, pode-se problematizar a visão culpabilizante de professores e educadores que mantém a família ou o contexto sociocultural de seus alunos como principais fatores para as dificuldades de aprendizagem, pouco refletindo a respeito de questões institucionais e da própria estrutura escolar e governamental, apesar do histórico da área em repensar como se constitui o fracasso escolar (ver, por exemplo, PATTO, 2010):

Em síntese, o presente estudo mostrou que muitos articuladores, com base em um modelo idealizado de família, culpabilizam os pais das crianças pelas dificuldades de aprendizagem geradoras do fracasso escolar. Há uma ideia preconcebida de que fatores como pobreza, falta de instrução formal dos pais e demais elementos presentes nas comunidades em que as famílias habitam são componentes que obstaculizam o desenvolvimento cognitivo e emocional da criança. (CORD et al., 2015, p. 46). 
Nesse mesmo sentido, foram encontrados estudos que apontam que as famílias muitas vezes percebem sua participação nas dificuldades de aprendizagem de seus filhos, assumindo essa participação, o que nem sempre é encontrado na visão dos professores. Assim, quando são ouvidos professores e pais a respeito das dificuldades de aprendizagem, encontram-se fatores em comum para as dificuldades, como questões governamentais de progressão continuada, no entanto, as famílias percebem também questões relacionadas à formação dos educadores, o que não é percebido pelos próprios (LIMA; CHAPADEIRO, 2015):

Os Encontros entre professoras e famílias [...] estão em localizar na criança ou em sua gestação a origem das dificuldades de aprendizagem. Houve responsabilização do sistema educacional no que se refere à progressão continuada, lotação de salas com alunos em diferentes níveis de aprendizagem e qualidade do ensino público. A família também foi relacionada ao problema. Referindo-se aos (des)Encontros, as professoras não se responsabilizaram pelos problemas de aprendizagem das crianças e não consideraram a possibilidade de suas próprias limitações; entretanto, os pais falaram do despreparo e da desqualificação dos professores. A maneira como as professoras relacionaram os problemas de aprendizagem às famílias diferiu de como as próprias famílias os relacionaram. Os pais foram os únicos que colocaram o desinteresse da criança pelos estudos como um dos fatores. (p. 498)

Pode-se, assim, destacar uma visão por parte de professores e educadores que culpabiliza a família e a encaminha aos serviços de saúde e de acompanhamento psicopedagógico sem procurar refletir a respeito de suas próprias dificuldades:

Os autores argumentam que, aparentemente, ao responsabilizarem a família pelos problemas de aprendizagem, os professores logo a procuram a fim de buscar soluções e, em seguida, fazem os encaminhamentos ao psicopedagogo para tratamento clínico. Não há, portanto, nenhuma alusão dos professores ao papel da própria escola nas dificuldades da criança, ficando os orientadores e psicólogos distantes do professor na busca de causas mais amplas para o problema e de soluções que envolvam também a instituição educacional. (SALVARI; DIAS, 2006, p. 255).

Para o presente estudo essas constatações servem como alerta para a atuação dos profissionais psicopedagogos: a ênfase que é dada para a participação familiar no acompanhamento de seus filhos também pode ser dividida com o que o sistema educacional possui de participação nas dificuldades de aprendizagem de seus alunos. É importante ressaltar, nesse sentido, uma atuação crítica e que contribua para que todos os envolvidos possam participar e desenvolverem-se no sentido de fortalecer as relações de aprendizagem das crianças e adolescentes atendidos. Apesar de se compreender o olhar psicopedagógico para a participação familiar, problematiza-se a maneira como esse trabalho é desenvolvido e

$$
\text { RELEDUC | ISE | v. } 3 \text { | n. } 1 \text { | dez. } 2020
$$


divulgado, na medida em que se corre o risco de se fortalecer uma visão em que a família é colocada como principal alvo de orientações e recomendações, contribuindo para uma visão enfraquecedora das relações familiares.

Em alguns estudos, apesar de fazerem ressalvas para a importância de uma visão integradora de diversos fatores para a compreensão das dificuldades de aprendizagem, encontrava-se um discurso que reforçava a necessidade de orientação das famílias que cobrariam das escolas funções que não eram delas, onde as instituições educativas muitas vezes apareciam como vítimas que procuravam as famílias e não recebiam retorno. Nesse sentido, é importante pensar nos movimentos históricos do que se demanda das famílias e do que se atribui às suas funções - Cunha (1997), por exemplo, escreve de um movimento de desqualificação das famílias para educar ao longo do tempo, evidenciado por ações e legislações que atribuíam às escolas a função primordial da educação. Atualmente se exige que as famílias voltem a educar, muitas vezes desconsiderando um panorama histórico e social que as afastou das atividades escolares e educacionais.

Salvari e Dias (2006) relatam, ainda, que as psicopedagogas, quando entrevistadas sobre os motivos para a decisão para um tratamento psicopedagógico, quando abordam o referencial escolar, falam que a decisão é por conta das produções escolares da criança, em que a escola encaminha para acompanhamento psicopedagógico por suas intervenções fracassarem. No entanto, fazem a seguinte ressalva:

Isso parece confirmar o pensamento de Bossa (2002) de que a escola, na atualidade, apresenta-se como o principal espaço social para a identificação das "anormalidades" infantis, mesmo que sob o risco de ancorar-se em uma concepção de criança ideal, construída ao longo da modernidade. Assim, a criança pode estar resistindo, com o seu sintoma, à excessiva normatização da escola, enquanto essa fracassa nas suas tentativas pedagógicas de remover o problema de aprendizagem, apelando, muitas vezes, aos especialistas em terapêuticas educativas na esperança de ver o fracasso reparado. (p. 255)

Nesse sentido, cabe à atuação do psicopedagogo uma reflexão a respeito das percepções das famílias e das escolas sobre as dificuldades de aprendizagem, contribuindo para esse difícil diálogo:

Além das outras funções do psicopedagogo na escola, como realizar orientação educacional, propor a intervenção no currículo, no projeto político pedagógico, na metodologia de ensino do professor, nas formas de aprender do professor, pode contribuir para a boa comunicação entre escola e família, favorecendo a um clima de confiança e estabelecendo um elo construtivo. (COSTA et al., 2018, p. 11)

$$
\text { RELEDUC | ISE } \mid \text { v. } 38 \text { | n. } 1 \text { | dez. } 2020
$$


Orientações sobre o que as famílias podem fazer para o fortalecimento da aprendizagem

Foram encontradas sugestões de ações ou mesmo orientações dos estudos a respeito do que as famílias poderiam fazer para contribuir para o fortalecimento dos processos de aprendizagem de seus filhos. O trabalho de Salvari e Dias (2006) destaca que quando as psicopedagogas entrevistadas chamavam a família para o acompanhamento psicopedagógico, além de investigar por anamnese aspectos cognitivos e afetivos para as dificuldades de aprendizagem das crianças atendidas, também era para a realização de orientações para essas famílias: "De modo geral, notamos que o objetivo desses encontros é orientar os pais para que possam favorecer as aprendizagens da criança" (p. 257). Nesse mesmo sentido, foram encontrados guias de ações para o acompanhamento das atividades escolares por parte das famílias de crianças com dificuldades de aprendizagem:

\begin{abstract}
Além de maior eficácia do sistema de ensino, na presente pesquisa ficou comprovado que é importante não somente o acompanhamento dos pais nos afazeres escolares, o estabelecimento de rotinas, o estabelecimento de horários para as diversas atividades do dia-a-dia e a reunião familiar, como também há a necessidade de os pais levarem seus filhos a passeios e darem a eles alguma atividade de lazer, além do oferecimento de brinquedos e atividades programadas fora da escola. (RIBEIRO; CIASCA; CAPELATTO, 2016, p. 172)
\end{abstract}

Um dos estudos encontrados, por exemplo, faz um levantamento de 14 orientações para as famílias realizarem com seus filhos (SOARES; SOUZA; MARINHO, 2004), tais como: definição de direitos e deveres com os filhos; manter uma rotina organizada e disponibilizar tempo para estar junto das crianças, como nos momentos de refeição; impor limites às crianças; supervisionar as atividades que a criança realiza; equilibrar proteção e incentivo à independência; disponibilizar um ambiente propício para o estudo; promover interações positivas; demonstrar afeto; ser um modelo de atuação para a criança, fazendo atividades de leitura, escrita, etc.; dialogar com a criança sobre seus temas de interesse; exigir de modo compatível com as habilidades e competências da criança; procurar relacionar o que a criança estuda na teoria com situações práticas, como viagens ou experiências; incentivar momentos de brincadeira; interessar-se pela vida do filho. Como se pode perceber são orientações simples e aplicáveis em qualquer situação, não necessariamente com famílias com dificuldades de

$$
\text { RELEDUC | ISE } \mid \text { v. } 39 \text { | n. } 1 \mid \text { dez. } 2020
$$


aprendizagem. Nesse sentido, esse estudo contribui para pensar com as escolas temas de reuniões com as famílias para serem discutidos e refletidos, na medida em que também se encontra que uma das queixas das famílias com relação às escolas é justamente a falta de orientações sobre como ajudar seus filhos nas atividades escolares.

Algo que os artigos permitiram refletir é a presença dessa demanda de orientações por parte dos pais, que muitas vezes, como foi visto anteriormente, são cobrados pelas dificuldades de aprendizagem dos filhos e se queixam, por sua vez, de também não receberem as orientações necessárias das escolas:

Entretanto, a exigência por parte da escola e a ausência de procedimentos e de orientações claras que viabilizem uma interação produtiva entre ambas as instituições têm resultado em contatos conflitivos entre pais e profissionais de instituições de ensino. (SOARES; SOUZA; MARINHO, 2004, p. 254).

A leitura e análise dos artigos, nesse sentido, incentiva a pensar na promoção de um maior contato entre educadores e famílias, de maneira mediada, como forma de contribuir para a conversa sobre essa relação conflituosa. Uma das atuações dos profissionais psicopedagogos, desta forma, poderá se dar na construção de uma relação de diálogo entre família e escola, contribuindo para a dissolução de visões culpabilizantes por ambos os lados. Dessa maneira, poderá promover, por exemplo, discussões sobre as temáticas elencadas: o que se quer dizer com a orientação "demonstrar afeto"? Como isso também se relaciona com a atuação do professor em ambiente de sala de aula? Quais as diferenças que família e escola percebem na maneira de realizar essa orientação? Por conseguinte, a realização de grupos de discussão e de terapia para as famílias de alunos com dificuldades de aprendizagem também foi encontrada em diferentes estudos, que serão abordados a seguir.

Grupos de orientaçãolapoio para os pais de crianças em acompanhamento psicopedagógico

Foram encontrados alguns estudos que procuravam promover atendimento para as famílias de crianças em acompanhamento psicopedagógico. Por exemplo, o estudo de Klumpp e Andrade (2013) procurou realizar uma pesquisa com as mães que estavam com suas crianças na fila de atendimento de uma clínica-escola:

As sessões de intervenção contribuíram positivamente para uma modificação nas relações de ensino-aprendizagem entre mães e filhos, já que, uma vez trabalhado o processo de aprendizagem das mães, as suas modalidades de ensino também foram trabalhadas e modificadas. (p. 91)

$$
\text { RELEDUC | ISE | v. } 30 \text { | n. } 1 \text { | dez. } 2020
$$


Desta forma, esse estudo (KLUMPP;ANDRADE, 2013) pôde contribuir e intervir com as famílias no sentido de ressignificarem suas próprias experiências de vida e de aprendizagem e assim também modificarem suas percepções a respeito das necessidades de aprendizagem de seus filhos. Outros artigos trouxeram estudos de caso com a abordagem sistêmica (por exemplo, BRAGA, 2009), intervindo especificamente com uma família e elaborando questões tanto com as crianças em atendimento quanto com suas famílias. Um dos estudos enfocou um trabalho desenvolvido por uma psicóloga escolar com uma visão sistêmica (ANDRADA, 2003), procurando também enfocar as questões institucionais envolvidas nas dificuldades de aprendizagem, pois também realizava grupos em conjunto com os docentes e as famílias dos alunos:

Foi neste cenário em construção que propus um trabalho junto às famílias e professores dos alunos apontados com dificuldade, procurando refletir com a equipe pedagógica (direção e orientação pedagógica), assim como junto com os professores e as famílias as funções que tais dificuldades poderiam estar exercendo na escola e/ou nas famílias, possibilitando ao aluno novas maneiras de estar nos determinados sistemas. (p. 172).

O estudo de Rolfsen e Martinez (2008), por sua vez, descreve um programa de intervenção de pais de crianças com dificuldades de aprendizagem. Basearam-se, para a proposta desse programa, nos trabalhos realizados no serviço de psicopedagogia do Hospital das Clínicas de Ribeirão Preto, por Parreira e Marturano (1999, apud ROLFSEN; MARTINEZ, 2008) e em outros estudos:

De acordo com Marturano e Ferreira (2004) o programa foi desenvolvido com $\mathrm{o}$ intuito de informar pais a respeito de como podem facilitar o aprendizado e adaptação escolar de seus filhos, a partir de temas discutidos com os pais, por meio de estratégias que promovem o empenho desses em atividades propostas e no compartilhamento de experiências na família. Os temas focalizados no programa abordam a organização, rotina e comunicação na família em relação às experiências do dia-a dia e o relacionamento entre a família e a escola (Parreira \& Marturano, 1999). (ROLFSEN; MARTINEZ, 2008, p. 177)

Assim, Rolfsen e Martinez (2008) desenvolveram um programa em seis sessões com pais, com dois encontros semanais de uma hora e meia. Aplicaram instrumentos para avaliação das crianças, para encaminhamento para outros serviços e também para conhecimento das famílias atendidas. Puderam constatar a pertinência do programa desenvolvido, destacando algumas modificações que poderiam ser realizadas, como aplicação de instrumentos antes e 
depois do programa de intervenção e realizar os encontros de maneira mais espaçada, pois duas vezes por semana impossibilitava a ida de todos os participantes em todos os encontros:

O Programa atendeu às necessidades de pais, podendo-se perceber interesse pelo conteúdo abordado e expectativas de poder ajudar seus filhos, em uma perspectiva de parceria entre família escola. Os relatos escritos e verbais apontaram para a pertinência das atividades propostas no programa, bem como das dinâmicas. Especial interesse foi demonstrado pelos pais em relação às temáticas que abordaram a organização familiar e a rotina, apoio à criança nas atividades escolares e participação no ambiente. (ROLFSEN; MARTINEZ, 2008, p. 185)

A partir dos artigos analisados, das demandas das famílias e das escolas, e também dos estudos de intervenção encontrados, pode-se sugerir guias para uma estrutura geral de trabalho que poderia ser realizado com as famílias de crianças em acompanhamento psicopedagógico. Desta forma, destacam-se alguns pontos importantes para o desenvolvimento desses grupos:

- Realizar em torno de seis a oito encontros em grupo de pais, na medida em que o grupo facilita a percepção de diversos fatores que afetam a aprendizagem, contribuindo para enfraquecer a sensação de culpa que as famílias já carregam quando seus filhos demonstram ter dificuldades de aprendizagem; o número de encontros não deve ser excessivo, para que seja possível das famílias participarem, e também não devem acontecer mais de um encontro semanal;

- Se possível, realizar um encontro das famílias com os professores e coordenadores das crianças atendidas, na medida em que essa troca de percepções nem sempre é ofertada e fortalece uma visão conflituosa entre família-escola;

- Promover encontros de orientações a respeito da rotina, da organização de atividades, sobre a realização de tarefas, sobre atividades de lazer e envolvimento com os filhos;

- Promover encontros em que as famílias possam ressignificar suas próprias histórias de aprendizagem, o que contribui para uma visão mais compreensiva das dificuldades que seus filhos podem estar apresentando. Nesse sentido, podem-se realizar dinâmicas que contribuam com as famílias para rememorar suas experiências no ambiente escolar e dinâmicas familiares associadas às suas experiências de aprendizagem, através do uso de desenhos, fotos, recortes e colagens.

Além disso, também foram encontrados nesses estudos de intervenção um destaque para a importância da atuação das universidades em atividades de extensão. Assim, a promoção desse tipo de grupo com os familiares em ambientes como clínicas-escola contribuiria e muito

$$
\text { RELEDUC | ISE | v. } 3 \text { | n. } 1 \text { | dez. } 2020
$$


para o aprofundamento dos estudos na área e para o fortalecimento das estratégias das famílias de crianças com dificuldades de aprendizagem.

\section{CONSIDERAÇÕES FINAIS}

O presente trabalho teve como principal objetivo investigar o papel que é atribuído às famílias no processo psicopedagógico pelos profissionais psicopedagogos. Desta forma, foi possível discutir e refletir a respeito de trabalhos que enfatizam a influência de modalidades de aprendizagem dos pais sobre às formas de aprender de seus filhos; a importância de determinadas estratégias familiares para o fortalecimento da aprendizagem dos seus filhos; a influência de relações específicas familiares sobre os processos de aprendizagem (por exemplo, a maior presença materna na aprendizagem, a influência do divórcio dos pais para a aprendizagem dos filhos, etc.); propostas de algumas orientações e realização de grupos de reflexão com as famílias de crianças e adolescentes com dificuldades de aprendizagem.

Alguns estudos com profissionais escolares indicam que a família é vista, muitas vezes, como principal fator para as dificuldades de aprendizagem encontradas nos filhos, o que revela aspectos políticos e sociais que se mantém na compreensão da sociedade para o fracasso escolar. Compreender a dificuldade como intrínseca ao aluno e ao contexto sociofamiliar contribui para que os professores considerem que têm pouco impacto na aprendizagem da criança, o que faz com que as questões de fracasso escolar mantenham a sua necessidade de reflexão e formação profissional.

Refletir sobre o papel que se atribui às famílias nos processos de aprendizagem tornase importante para a realização de um trabalho psicopedagógico não culpabilizante das relações familiares, mas que procure fortalecer essas relações e os processos de aprendizagem. Foi possível, ao longo do trabalho, pensar no papel que a própria psicopedagogia pode fazer para fortalecer um diálogo entre família e escola, na medida em que a maneira como os profissionais irão atuar com essas famílias corre o risco de lhes estigmatizar e culpabilizar ainda mais. Para exemplificar: quando uma família busca apoio psicopedagógico usualmente já foi encaminhada pela escola, que também já terá feito observações a respeito do comportamento de seu filho em sala de aula e suas dificuldades. Essa família já chega preocupada em não estar fazendo algo ou estar cometendo erros na educação de seus filhos. Se as orientações forem dadas pelo profissional de maneira que permita pouco diálogo e reflexão, só fortalecerão nessa família a

$$
\text { RELEDUC | ISE | v. } 3 \text { | n. } 1 \text { | dez. } 2020
$$


ideia de que existe uma receita pronta para educar e que eles não estavam seguindo. Nesse sentido, o presente artigo se propôs a problematizar o papel atribuído às famílias nos processos psicopedagógicos de maneira a que se procure construir junto com as famílias e com as instituições educativas novas formas de aprendizagem e de desenvolvimento, que sejam criadas e vividas por todos os atores envolvidos.

\section{REFERÊNCIAS}

ALMEIDA, A. P. D. Quando o vínculo é doença: a influência da dinâmica familiar na modalidade de aprendizagem do sujeito. Rev. Psicopedagogia, São Paulo, v. 28, n. 86, p. 201-213, 2011. Disponível em $<$ http://pepsic.bvsalud.org/scielo.php?script=sci_arttext\&pid=S010384862011000200011\&lng=pt\&nrm=iso>. acesso em 01 ago. 2018.

ANDRADA, E. G. C. Família, escola e a dificuldade de aprendizagem: intervindo sistemicamente. Psicol. Esc. Educ. (Impr.), Campinas, v. 7, n. 2, p. 171-178, Dec. 2003 . Disponível em: <http://www.scielo.br/scielo.php?script=sci_arttext\&pid=S1413$85572003000200007 \& \operatorname{lng}=\mathrm{en} \& \mathrm{nrm}=$ iso $>$. Aceso em 30 out. 2018.

BORGES, M. C.; DALBERIO, O. Aspectos metodológicos e filosóficos que orientam as pesquisas em educação. Revista Iberoamericana De Educación, 43(5), p. 1-10. Disponível em: https://rieoei.org/RIE/article/view/2299. Acesso em 02 ago. 2018.

BRAGA, A. L. A. Psicopedagogia e constelação familiar sistêmica: um estudo de caso. Rev. Psicopedagogia, São Paulo, v. 26, n. 80, p. 274-285, 2009 . Disponível em $<$ http://pepsic.bvsalud.org/scielo.php?script=sci_arttext\&pid=S0103$84862009000200012 \& \operatorname{lng}=$ pt\&nrm=iso>. Acesso em 30 out. 2018.

BRAGA, S.S.; SCOZ, B. J. L. ; MUNHOZ, M. L. P. Problemas de aprendizagem e suas relações com a família. Rev. Psicopedagogia, São Paulo , v. 24, n. 74, p. 149-159, 2007 . Disponível em <http://pepsic.bvsalud.org/scielo.php?script=sci_arttext\&pid=S010384862007000200006\&lng=pt\&nrm=iso>. Acesso em 30 out. 2018.

COLOMER, T.; MASOT, M.T.; NAVARRO, I. A avaliação psicopedagógica. IN. SÁNCHEZ-CANI, M.; BONALS, J. (orgs.) Avaliação psicopedagógica. Porto Alegre: Artmed, 2008, pp. 15-23

CORD, D.; GESSER, M.; NUNES, A. S. B.; STORTI, M. M. T. As Significações de Profissionais que Atuam no Programa Saúde na Escola (PSE) Acerca das Dificuldades de Aprendizagem: Patologização e Medicalização do Fracasso Escolar. Psicol. cienc. prof. [online]. 2015, vol.35, n.1, pp.40-53. Desponível em: http://www.scielo.br/scielo.php?script=sci_arttext\&pid=S1414$98932015000100040 \& \operatorname{lng}=$ en\&nrm=iso. Acesso em 30 out.2018

$$
\text { RELEDUC | ISE | v. } 3 \text { | n. } 1 \text { | dez. } 2020
$$


COSTA, T. C. O., OLIVEIRA, N. S. A., ABREU, C.

S., ABREU, A. S., SOUZA, E. S. A., BRUNA, S. S., BRUNA, M. P.

A psicopedagogia e a família no processo ensino

aprendizagem. Revista Científica Multidisciplinar Núcleo do Conhecimento. Ano 03, Ed.

09, Vol. 1, pp. 35-50, Setembro de 2018. Disponível em: <

https://www.nucleodoconhecimento.com.br/educacao/psicopedagogia>. Acesso em 30 out.

2018.

CUNHA, M.V. Da. A desqualificação da família para educar. Cad. De Pesquisas, n. 102, pp. 46-64. Novembro 1997. Disponível em:

http://www.fcc.org.br/pesquisa/publicacoes/cp/arquivos/227.pdf. Acessado em 19 de Out. de 2015.

GOMES, M. B. S. H.; VALE-DIAS, M. L. A família e a construção das modalidades de aprendizagem. Revista de Estudios e Investigación en Psicología y Educación, [S.1.], p. 310-315, dez. 2017. Disponivel em:

<http://revistas.udc.es/index.php/reipe/article/view/reipe.2017.0.05.2807>. Acesso 01 ago. 2018.

KLUMPP, C.F.B., ANDRADE, M. S. Mães de crianças com dificuldades de aprendizagem: análise compreensiva do processo de intervenção. Rev. Psicopedagogia, 2013;30(92):81-93. Disponível em: < http://pepsic.bvsalud.org/scielo.php?script=sci_arttext\&pid=S0103$84862013000200002>$. Acesso em 30 out. 2018.

LIMA, B. H., CHAPADEIRO, T. A.C, Encontros e (des)encontros no sistema família-escola. Psicologia Escolar e Educacional [online] 2015, 19 (Setembro-dezembro). Disponível em::<http://www.redalyc.org/articulo.oa?id=282343250009>. Acesso em 30 out. 2018

MARTURANO, E. M.; ELIAS, L. C. S. Família, dificuldades no aprendizado e problemas de comportamento em escolares. Educ. rev., Curitiba, n. 59, p. 123-139, Mar. 2016.

Disponível em: <http://www.scielo.br/scielo.php?script=sci_arttext\&pid=S010440602016000100123\&lng=en\&nrm=iso>. Acesso em 01 Ago. 2018.

NETO, F., CARDOSO, A. C. , KAIHAMI, H.N., OSTERNACK, K. , NASCIMENTO, A.F., BARBIERI, C.L.A. Dificuldade de aprendizagem no Ensino Fundamental e Médio: a percepção de professores de sete escolas públicas de São Paulo - SP. Rev. Psicopedagogia 2015;32(97):26-37. Disponível em:

http://pepsic.bvsalud.org/scielo.php?script=sci_arttext\&pid=S0103-84862015000100004. Acesso em 30 out. 2018.

NOGUEIRA, M.A. Família e escola na contemporaneidade: os meandros de uma relação.

Educação e Realidade, Porto Alegre, RS, v. 31, n. 2, pp. 155-170. Jul./dez. de 2006.

Disponível em: <http://seer.ufrgs.br/educacaoerealidade/article/viewFile/6850/4121>. Acesso em 27 jul. 2018.

OLIVEIRA, C. B. E. de; MARINHO-ARAUJO, C. M. A relação família-escola: intersecções e desafios. Estud. psicol. (Campinas), Campinas, v. 27, n. 1, p. 99-108, Mar. 2010. 
Disponível em: <http://www.scielo.br/scielo.php?script=sci_arttext\&pid=S0103166X2010000100012\&lng=en\&nrm=iso>. Acesso em 27 de jul. de 2018.

PATTO, M. H. De. S. (1990) A produção do fracasso escolar: histórias de submissão e rebeldia. São Paulo: Casa do Psicólogo, 2010.

RIBEIRO, R.; CIASCA, S. M.; CAPELATTO, I. V. Relação entre recursos familiares e desempenho escolar de alunos do $5^{\circ}$ ano do ensino fundamental de escola pública. Rev.

Psicopedagogia, São Paulo, v. 33, n. 101, p. 164-174, 2016 . Disponível em $<$ http://pepsic.bvsalud.org/scielo.php?script=sci_arttext\&pid=S0103$84862016000200006 \& \operatorname{lng}=$ pt\&nrm=iso>. Acesso em 30 out. 2018.

ROLFSEN, A. B.; MARTINEZ, C. M. S. Programa de intervenção para pais de crianças com dificuldades de aprendizagem: um estudo preliminar. Paidéia (Ribeirão Preto), Ribeirão Preto, v. 18, n. 39, p. 175-188, 2008 . Disponível em:

$<$ http://www.scielo.br/scielo.php?script=sci_arttext\&pid=S0103-

863X2008000100016\&lng=en\&nrm=iso>. Acesso em: 30 out. 2018.

SALVARI, L.F. C.; DIAS, C. M. S. B. Os problemas de aprendizagem e o papel da família: uma análise a partir da clínica. Estud. psicol. (Campinas), Campinas , v. 23, n. 3, p. 251259, Setembro 2006. Disponível em:

<http://www.scielo.br/scielo.php?script=sci_arttext\&pid=S0103-

166X2006000300004\&lng=en\&nrm=iso>. Acesso em 30 out. 2018.

SARAIVA, L. A.; WAGNER, A. A Relação Família-Escola sob a ótica de Professores e Pais de crianças que frequentam o Ensino Fundamental. Ensaio: aval.pol.públ.Educ., Rio de Janeiro , v. 21, n. 81, p. 739-772, Dez. 2013 . Disponível em:

<http://www.scielo.br/scielo.php?script=sci_arttext\&pid=S0104-

$40362013000400006 \& \operatorname{lng}=$ en\&nrm=iso>. Acesso em 27 de Jul de 2018.

\section{SILVA, B. K. M. FAMÍLIA E A ESCOLA NA APRENDIZAGEM DA CRIANÇA COM}

TDAH: a necessidade de uma parceria ativa e produtiva. Pedagogia em Ação, [S.1.], v. 7, n. 1, dez. 2015. Disponível em:

<http://periodicos.pucminas.br/index.php/pedagogiacao/article/view/11042>. Acesso em: 01 ago de 2018.

SOARES, M. R. Z.; SOUZA, S. R.; MARINHO, M. L.. Envolvimento dos pais: incentivo à habilidade de estudo em crianças. Estud. psicol. (Campinas), Campinas, v. 21, n. 3, p. 253 260, Dez. 2004. Disponível em:

<http://www.scielo.br/scielo.php?script=sci_arttext\&pid=S0103-

166X2004000300009\&lng=en\&nrm=iso>. Acesso em 30 out. 2018.

TABILE, A.F., JACOMETO, M.C.D. Fatores influenciadores no processo de aprendizagem: um estudo de caso. Rev. Psicopedagogia 2017;34(103):75-86. Disponível em:< http://www.revistapsicopedagogia.com.br/detalhes/519/fatores-influenciadores-no-processode-aprendizagem--um-estudo-de-caso>. Acesso em 30 out.2018. 